\title{
DOES AWARENESS AND EXPERIENCE OF MALE REPRODUCTIVE HEALTH CHALLENGES AFFECT RISKY SEXUAL BEHAVIOURS OF MEN IN NIGERIA
}

\author{
Uyi E. Osadolor ${ }^{1 \star}$, Emmanuel O. Amoo ${ }^{2}$, Dominic O. Azuh ${ }^{3}$, Joy O. Nwosu ${ }^{4}$ \\ ${ }^{1} \mathrm{Mr}$, Covenant University, Nigeria, uyiosadolore@gmail.com \\ ${ }^{2} \mathrm{Dr}$, Covenant University, Nigeria, emma.amoo@covenantuniversity.edu.ng \\ ${ }^{3} \mathrm{Dr}$, Covenant University, Nigeria, dominic.azuh@covenantuniversity.edu.ng \\ ${ }^{4} \mathrm{Ms}$, Covenant University, Nigeria, joyonuchinwosu@gmail.com \\ ${ }^{*}$ Corresponding author
}

\begin{abstract}
Risky sexual behaviours among men are well-evident in sub-Saharan Africa and there is a wide perspective that men awareness of reproductive diseases is low, despite rising prevalence of reproductive diseases. While there are literatures on risky sexual behaviours and prevalence of reproductive health diseases of men alone, little is known about whether awareness and experience of male reproductive challenges affect risky sexual behaviours of men in Lagos and Ogun States in Nigeria. This study therefore seeks to examine the awareness and experience of male reproductive challenges and how it affects risky sexual behaviours of men in Nigeria. Primary data was used for this study. Two levels of analysis namely univariate and multivariate was used to analyse the data. The univariate statistics involved descriptive statistics such as frequencies and means. The multivariate analysis involved the use of logistic regression technique to estimate whether awareness and experience of male reproductive challenges affect risky sexual behaviours of men in Nigeria. The result confirms that awareness and experience of reproductive health challenges affect risky sexual behaviour in men. This study helps policy makers, NGOs and government in emanating policies and legislation aimed at militating against risky sexual behaviours. Furthermore, NGOs and government could set up health centres which are for men's reproductive and sexual health alone, this would encourage men to go for sexual and reproductive health screening.
\end{abstract}

Keywords: Risky sexual behaviours, male sexual behaviour, men's reproductive challenges

\section{INTRODUCTION}

Reproductive health relates to reproductive and sexual function and dysfunction. It implies a state of physical, mental and social wellbeing and not merely the absence of disease or sickness, in all matters relating to the functions and processes of the reproductive system in all stages of life (Amoo, 2012; Swanson et al., 2004; United Nations, 1994). Reproductive health implies that people are able to have a satisfying and safe sex life and that they have the capability to reproduce and the freedom to decide if, when and how often to do so (World Health Organization, 2018). 
Male reproductive health therefore entails the proper functioning of the male reproductive system. It can further be defined as a state of complete physical, social, and mental health and not merely the absence of disease or infirmity, in all matters relating to men's reproductive system at all stages if life (Amoo, 2012; International Conference on Population and Development (ICPD), 1994). All other conferences prior to the international conference on population development (ICPD) 1994 was viewing population reduction from only the female point of view until ICPD 1994 when the unmet need for male reproductive health involvement was brought to limelight.

Reproductive health challenge on the other hand are factors or conditions that affect the ability of people to have a satisfying and safe sex life thereby inhibiting their capacity to reproduce and impinging their freedom to decide if, when and how often to do so(Amoo, 2012; ICPD, 1994) (World Health Organization, 2018). Generally, difficulties such as impotence, testicular infections, impairment in reproductive activities, arousal difficulties, HIV/AIDS, premature ejaculation, infertility and so on at any stage of the reproductive health life of a man relates to male reproductive health challenge (De Vincentis, Tartaro, Rochira, \& Santi, 2021; Faith Osasumwen Olanrewaju, et al., 2019).

Risky sexual behaviours are sexual behaviours that endanger the life of those participating in it. It involves number of sexual partners, sexual acts, sexual orientation, early age at first sexual intercourse, unprotected sex with partners that pose a risk and unidentified, undermanaged and untreated sexually transmitted infections (STI's) ((Kebede, Molla, \& Gerensea, 2018; Clifford \& Oluwaseyi, 2017)

Overtime, different studies have linked risky sexual behaviour to sexual experience.

This study is based on the Health Belief Model (Hochbaum, 1958) which holds that personal beliefs or perceptions held about a disease and the methods readily available to reduce its occurrence is the major factor determining health behaviour. This argues that the understanding of reproductive health challenges would help males to reduce or cut out any factor that pre-disposes them to it.

This study seeks to examine the awareness and experience of male reproductive challenges and how it affects risky sexual behaviours of men in Nigeria. This study is vital because not only does male reproductive health challenge affect men it also affects women directly as the men can be carriers of disease and potential agents of transmission (Amoo, 2012; International Conference on Population and Development (ICPD), 1994).

\section{METHODS}

\subsection{Study design}

This quantitative study utilized a survey research approach to generate data on the men's awareness and experience of reproductive health challenges and on risky sexual behaviours in Ikorodu and Ado-Odo/Ota Local government areas (LGAs) of Lagos and Ogun States, located in Southwest Nigeria. The Yorubas are mainly the inhabitants, with clusters of Igbo and Hausas living in the area.

\subsubsection{Study population}

The study population comprised of men aged between 15 and 64 years old living in Lagos and Ogun States of Nigeria. In determining the sample size, the Israel Gleen's sampling size determination was applied. A sample size of 775 was arrived at after computation for both study locations. A multistage sampling procedure was adopted in the selection of the respondents from the two Local Governments Areas (LGAs) randomly selected from both Lagos (Ikorodu LGA) and Ogun (Ado-Odo/Ota LGA) States.

\subsection{Data Collection}

Data was collected with the aid of an interviewer-administered structured questionnaire. Eight research assistants who were currently enrolled in a university program were trained and used for the data collection procedure. The questionnaire was divided into the following sections: socio-demographic characteristics, socioeconomic characteristics, awareness and experience of reproductive health challenges/ diseases and risky sexual behaviours. The questionnaire was pretested among 70 men in one enumeration area randomly selected in Ado-Odo/Ota Local Government Area and necessary adjustments were made.

\subsection{Study Variables}

In this study, risky sexual behaviour was defined as any activity that increases the probability of a person being infected as a result of sexual activity with another person infected with a sexually transmitted infection (Srahbzu \& Tirfeneh, 2020). Risky sexual behaviours comprise activities such as having multiple sexual 
partners, sex with prostitutes, none use of condoms and so on.

Study variables used in determining factors influencing risky sexual behaviours included the sociodemographic profile of the respondents such as age, marital status, place of residence, educational attainment and average monthly income. For the awareness and experience of reproductive health challenges, common men's reproductive health challenges/diseases were listed in the questionnaire and respondents were asked to identify the male reproductive challenges they knew and the diseases they had experienced or are currently experiencing.

\section{DATA ANALYSIS}

Statistical package for social sciences (SPSS) version 20 was used to code, check and process the data obtained. Two levels of analysis namely univariate and multivariate were used to analyse the data. The univariate statistics involved descriptive statistics such as frequencies and percentage. The multivariate analysis involved the use of logistic regression technique to estimate whether awareness and experience of male reproductive challenges affect risky sexual behaviours of men in Lagos and Ogun States of Nigeria.

\section{RESULTS}

The survey revealed the demographic characteristics of the respondents. Specifically, the sample comprised of males who were never married, currently married and divorced. Table 1 reveals that most of the respondents were currently married (48.3\%) while men who were never married and divorced constituted 42.7\% and 9\% respectively. Ikorodu LGA (Lagos) and Ado-Odo/Ota LGA (Ogun) States were the survey locations. These States were randomly selected out of the six States in Southwest Nigeria. Respondents were selected from both rural and urban areas of the two States. In all, $36 \%$ of the respondents were from rural areas while $63.1 \%$ are urban residents.

In any analysis related to sexual and reproductive challenges, age is a key factor. The result shows that the mean age of the population as at last birthday was relatively 35 years while the median age was 33 years. The detailed result revealed that men in the age group 15-24 years were the most dominant age group, men in the age group 25-34 constituted 25.5\%. The least age group were men between the ages of 55-64 years.

The education profile revealed that $4.3 \%$ of the respondents have never experienced any form of formal education. However, respondents who had attained university education comprised the majority of the respondents in the study locations. Those with primary and secondary education constituted $3.5 \%$ and $32.8 \%$ respectively.

As indicated in Table 1,78.4\% of the respondents earn an average income below N80,000. While a little more than one-fifth of the respondents earn above $\mathrm{N} 80,000$. Furthermore, Table 1 reveals that more than half of the respondents were engaged in sexual relationships with more than one person (73\%), with less than one-fourth indicating they have only one sexual partner. Again, the survey result shows that only $33.3 \%$ of the respondents made use of condoms when they engaged in sexual intercourse.

The survey participants were questioned on whether they are currently having a sexual relationship with a prostitute; the result revealed that $29.8 \%$ of the respondents were currently engaged in sexual relationships with a commercial sex worker. In assessing the level of awareness of the respondents to common reproductive and sexual challenges, the respondents were questioned to know their level of awareness. The result shows that majority of the respondents were unaware of reproductive health challenges (70.8\%). The result further showed that only $23.4 \%$ of the population had ever experienced or are currently experiencing reproductive health challenges (Table 1).

Table 1: Demographic Profile of the Respondents

\begin{tabular}{|l|l|l|l|c|l|}
\hline Selected Variables & Freq $(\mathbf{n}=\mathbf{7 7 5})$ & $\%$ & Selected Variables & Freq $(\mathbf{n}=\mathbf{7 7 5})$ & $\%$ \\
\hline State & & & Place of Residence & & \\
\hline Lagos & 388 & 50.1 & Rural & 286 & 36.9 \\
\hline Ogun & 387 & 49.9 & Urban & 489 & 63.1 \\
\hline Age Group & & & Marital Status & & \\
\hline $15-24$ & 225 & 29.0 & Never married & 331 & 42.7 \\
\hline $25-34$ & 198 & 25.5 & Currently married & 374 & 48.3 \\
\hline $35-44$ & 161 & 20.8 & Divorced/Others & 70 & 9.0 \\
\hline $45-54$ & 117 & 15.1 & $\begin{array}{l}\text { Average monthly } \\
\text { income }\end{array}$ & & \\
\hline
\end{tabular}


Proceedings of SOCIOINT 2021 8th International Conference on Education and Education of Social Sciences 14-15 June, 2021

\begin{tabular}{|l|l|l|l|c|l|}
\hline $55-64$ & 74 & 9.5 & No income & 89 & 11.5 \\
\hline Level of Education & & & Below N20,000 & 51 & 6.6 \\
\hline No Schooling & 33 & 4.3 & N20,000- N39,999 & 157 & 20.3 \\
\hline Primary level & 27 & 3.5 & N40,000- N59,999 & 209 & 27 \\
\hline Secondary Level & 254 & 32.8 & N 60,000- N 79,999 & 101 & 13 \\
\hline University level & 461 & 59.5 & N80,000 \& above & 168 & 21.6 \\
\hline Multiple sex partners & & & Condom use & & \\
\hline Yes & 566 & 73 & Yes & 258 & 33.3 \\
\hline No & 209 & 27 & No & 517 & 66.7 \\
\hline $\begin{array}{l}\text { Sex with commercial } \\
\text { sex worker }\end{array}$ & & & Awareness of RC & & \\
\hline Yes & 231 & 29.8 & Aware & 226 & 29.2 \\
\hline No & 544 & 70.2 & Unaware & & 70.8 \\
\hline Experienced RC & & & & & \\
\hline Yes & 181 & 23.4 & & & \\
\hline No & 594 & 76.6 & &
\end{tabular}

Source: Field survey, 2021

In Table 2 the interrelationship between the awareness of male reproductive challenges and risky sexual behaviours were computed to identify the effect of the awareness of reproductive challenges on risky sexual behaviours in the study locations. Risky sexual behaviours which is the predictor variable is measured by the following variables; multiple sexual partners, condom use and sex with commercial sex workers. Table 2 indicates that the overall percentage of $70.8 \%$ provided an overview that the outcome result is an accurate prediction for up to 70.8 cases. Furthermore, the two indices (Cox and shell R-square (R2) and Nagelkerke (R) ) show that the variation in the dependent variable is explained by the predictor variables. Thus the Cox and shell R-square (R2) of 0.19 implies that $19 \%$ of the variation are being explained by the independent variables, while the Nagelkerke $(R)$ of 0.13 indicates that $13 \%$ of the variation could be explained by the predictors. Table 2 indicated that men who had multiple sexual partners were 0.549 times less likely to be aware of reproductive health challenges/diseases. The relationships between the variables are statistically significant at $5 \%$. The confidence interval reveals that we are $95 \%$ confident that the correlation between multiple sexual partnerships and been aware of reproductive health challenges is between $0.38-0.80$.

Again, the result shows that men who make use of condoms during sexual intercourse were 0.950 times more likely to be aware of reproductive health challenges/diseases. The confidence interval reveals that we are $95 \%$ confident that the correlation between condom use and been aware of reproductive health challenges is between $0.68-1.32$.

Furthermore, Table 2 reveals that men who have sex with commercial sex workers were 1.176 times less likely to be aware of reproductive health challenges/diseases. The confidence interval reveals that we are $95 \%$ confident that the correlation between condom use and been aware of reproductive health challenges is between $0.83-1.66$.

Table 2: Logistic Regression Estimating the Effects of the Awareness of Male Reproductive Challenges on Risky Sexual Behaviours

\begin{tabular}{|c|c|c|c|c|c|c|}
\hline Selected variables & B & S.E. & Wald & Sig. & Exp(B) & 95\% C.I. \\
\hline Multiple sex partner & -0.600 & 0.195 & 9.508 & 0.002 & 0.549 & $0.375-0.804$ \\
\hline Condom use & 0.051 & 0.168 & 0.094 & 0.759 & 0.950 & $0.683-1.321$ \\
\hline $\begin{array}{c}\text { Commercial sex } \\
\text { Workers }\end{array}$ & -0.162 & 0.177 & 0.838 & 0.360 & 1.176 & $0.831-1.663$ \\
\hline Constant & 1.310 & 0.180 & 53.281 & 0.000 & 3.707 & \\
\hline
\end{tabular}

Nagelkerke $R$ Square $=0.19 ;$ Cox \& Snell $R$ Square $=0.13$

Overall Percentage $=70.8 \% ;{ }^{* *} \mathrm{P}<0.05$

Source: Field survey 2021

In Table 3 the interrelationship between the experience of male reproductive challenges and risky sexual behaviours were computed to identify the effect of having experienced reproductive challenges on risky sexual behaviours in the study locations. Risky sexual behaviours which is the predictor variable is measured 
by the following variables; multiple sexual partners, condom use and sex with commercial sex workers. Table 3 indicates that the overall percentage of $76.6 \%$ provided an overview that the outcome result is an accurate prediction for up to 76.6 cases. Furthermore, the two indices (Cox and shell R-square (R2) and Nagelkerke (R) ) show that the variation in the dependent variable is explained by the predictor variables. Thus the Cox and shell R-square (R2) of 0.25 implies that $25 \%$ of the variation are being explained by the independent variables, while the Nagelkerke $(R)$ of 0.37 indicates that $37 \%$ of the variation could be explained by the predictors. Table 3 indicated that men who had multiple sexual partners were 1.036 times more likely to have experienced reproductive health challenges/diseases. The confidence interval reveals that we are $95 \%$ confident that the correlation between multiple sexual partnerships and been aware of reproductive health challenges is between $0.71-1.52$.

Again, the result shows that men who make use of condoms during sexual intercourse were 0.538 times more likely to have experienced reproductive health challenges/diseases. The relationships between the variables are statistically significant at $5 \%$. The confidence interval reveals that we are $95 \%$ confident that the correlation between condom use and been aware of reproductive health challenges is between $0.38-$ 0.76 .

Furthermore, Table 3 reveals that men who have sex with commercial sex workers were 1.669 times less likely to have experienced reproductive health challenges/diseases. The relationships between the variables are statistically significant at 5\%. The confidence interval reveals that we are $95 \%$ confident that the correlation between condom use and been aware of reproductive health challenges is between 1.12-2.49.

Table 3: Logistic regression estimating the effects of the experience of male reproductive challenges on risky sexual behaviours

\begin{tabular}{|c|c|c|c|c|c|c|}
\hline Selected variables & B & S.E. & Wald & Sig. & $\operatorname{Exp(B)}$ & $95 \%$ C.I. \\
\hline Multiple sex partner & 0.036 & 0.194 & 0.034 & 0.855 & 1.036 & $0.708-1.516$ \\
\hline Condom use & 0.621 & 0.176 & 12.500 & 0.000 & 0.538 & $0.381-0.758$ \\
\hline $\begin{array}{c}\text { Commercial sex } \\
\text { workers }\end{array}$ & -0.512 & 0.203 & 6.355 & 0.012 & 1.669 & $1.121-2.486$ \\
\hline Constant & 1.254 & 0.177 & 50.452 & 0.000 & 3.503 & \\
\hline
\end{tabular}

Nagelkerke R Square $=0.25 ;$ Cox \& Snell R Square $=0.37$

Overall Percentage $=76.6 \% ;{ }^{* *} \mathrm{P}<0.05$

Source: Field survey 2021

\section{DISCUSSION}

The high proportion of those that didn't use condom in their last sexual experience shows the extent of risky sexual behaviour among men (Clifford \& Oluwaseyi, 2017). The result is in tandem with past reports. A 2015 study in Nigeria reported that $79.5 \%$ of men that participated in the study did not make use of condoms even though they were sexually active (Amoo, et al., 2015). A study carried out in southern Africa showed that between $50-60 \%$ of respondents engaged in sexual activities without the use of condoms (Eaton, Flisher, \& Aarø, 2003).

About $73 \%$ of respondents have multiple sexual partners which is in line with a study in Ethiopia that showed that being male was found to be associated with risky sexual practices (Muche, Kassa, Berhe, \& Fekadu, 2017). Another report showed that more than $80 \%$ of the men who were already having sex had multiple sexual partners as opposed to women (Clifford \& Oluwaseyi, 2017). In a study carried out in Osun state by (Olowookere, Olajide, Olajide, \& Omisore, 2020), also found out that being male was significantly associated with multiple sexual partners.

More than $70 \%$ of respondents were not aware of reproductive health challenges. This is in line with a study carried out in India where the participants of the study had poor knowledge score, indicating poor sexual knowledge (Dutt \& Manjula, 2017). Another study among adolescents in India showed a consistently low 
knowledge level across all factors that relate to awareness of reproductive challenges (Sivagurunathan, Umadevi, Rama, \& Gopalakrishnan, 2015).

This survey uncovered that $76.6 \%$ of all participants have not experienced any reproductive challenge. This is in line with data from National Agency for the Control of AIDS (NACA) that showed that the prevalence rate for HIV/AIDS is $1.3 \%$ and $1.2 \%$ in Lagos and Ogun state respectively (National Agency for the Control of AIDS, 2019). It can also be due to the fact that men rarely go to the hospital for their health needs.

\section{CONCLUSION}

Awareness and experience of male reproductive challenges unequivocally influences risky sexual reproductive behaviour. Experience and awareness of reproductive health challenges have led to caution on the part of men as it relates to their sexual behaviour. With the result showing that men who had multiple sexual partners were 0.549 times less likely to be aware of reproductive health challenges/diseases. Therefore promoting campaigns which are targeted at bringing awareness of the consequences of risky sexual behaviours is important. Also, this study can be used as a reference point by policy makers, NGOs and government in emanating policies and legislation aimed at militating against risky sexual behaviours. Furthermore, NGOs and government could set up health centres which are for men's reproductive and sexual health alone; this would encourage men to go for sexual and reproductive health screening.

\section{ACKNOWLEDGEMENTS}

The authors received financial support for the publication of this article from Covenant University.

\section{REFERENCE LIST}

Amoo, E. (2012). Male reproductive health challenges and conjugal relationships among the yoruba in Lagos and Osun states of Nigeria. Covenant University: http://eprints.covenantuniversity.edu.ng/4095/1/theses.covenantuniversity.edu.ng_bitstream_handle 1 .

Amoo, E. O., Oni, G. A., Ajayi, M. P., Idowu, A. E., Fadayomi, T. O., \& Omideyi, A. K. (2015). Are Men's Reproductive Health Problems and Sexual Behavior Predictors of Welfare? American Journal of Men's Health.

Clifford, O., \& Oluwaseyi, D. S. (2017). Ethnicity, gender and risky sexual behaviour among Nigerian youth: an alternative explanation. Reproductive Health, 14(16). doi:https://doi.org/10.1186/s12978-0170284-7

De Vincentis, S., Tartaro, G., Rochira, V., \& Santi, D. (2021, March 05). HIV and Sexual Dysfunction in Men. Journal of Clinical Medicine, 10(5). doi:DOI: 10.3390/jcm10051088

Dutt, S., \& Manjula, M. (2017). Sexual knowledge, attitude, behaviors and sources of influences in Urban college youth: A study from India. Indian Journal of Social Psychiatry, 33(4), 319-326. doi:10.4103/0971-9962.218602

Eaton, L., Flisher, A. J., \& Aarø, L. E. (2003). Unsafe sexual behaviour in South African youth. Social Science \& Medicine, 56(1), 149-165. doi:https://doi.org/10.1016/S0277-9536(02)00017-5

Faith Osasumwen Olanrewaju, Lady Adaina Ajayi, Ejiroghene Loromeke, Adekunle Olanrewaju, Tolulope Allo, Onwuli Nwannebuife, \& Emmanuel O Amoo. (2019). Masculinity and men's health-seeking behaviour in Nigerian academia. Cogent Social Sciences, 5(1). doi: 10.1080/23311886.2019.1682111

Hochbaum, G. M. (1958). Pubic Participation in Medical Screening Programs: A Socio- Psychological Study. Public Health Service Publication. doi:10.1080/02331880902825901

International Conference on Population and Development (ICPD). (1994 , September 8). International Conference on Population and Development (ICPD) . Retrieved from UNFPA - United Nations Population Fund.: https://www.unfpa.org/events/international-conference-population-anddevelopment-icpd

Kebede, A., Molla, B., \& Gerensea, H. (2018). Assessment of risky sexual behavior and practice among 
Aksum University students, Shire Campus, Shire Town, Tigray, Ethiopia. BMC Res Notes, 11(88). doi:https://doi.org/10.1186/s13104-018-3199-7

Muche, A. A., Kassa, G. M., Berhe, A. K., \& Fekadu, G. A. (2017). Prevalence and determinants of risky sexual practice in Ethiopia: Systematic review and Meta-analysis. Reproductive Health, 14(113). doi:https://doi.org/10.1186/s12978-017-0376-4

National Agency for the Control of AIDS. (2019). Nigeria Prevalence Rate. Retrieved from National Agency for the Control of AIDS: https://naca.gov.ng/nigeria-prevalence-rate/

Olowookere, S., Olajide, F., Olajide, A., \& Omisore, A. (2020). Factors associated with inconsistent condom use and multiple sexual partners among adolescents in South Western Nigeria. African Journal of Medicine and Medica sciences, 49(3).

Sivagurunathan, C., Umadevi, R., Rama, R., \& Gopalakrishnan, S. (2015). Adolescent Health: Present Status and Its Related Programmes in India. Are We in the Right Direction? Journal of Clinical and Diagnostic Research, 9(3). doi: 10.7860/JCDR/2015/11199.5649

Swanson, D. A., A., D., Siegel, J. S., \& Shryock, H. S. (2004). The Methods and materials of demography. Elsevier Academic Press.

United Nations. (1994). International Conference on Population and Development Programme of Action. . Retrieved from In the International Conference on Population and Development Cairo. UNFPA.: http://www.unfpa.org/publications/international-conference-population-and-development-prograeaction\#

World Health Organization. (2018). Reproductive Health. Retrieved from World Health Organization Western Pacific: https://www.who.int/westernpacific/health-topics/reproductive-health 